\title{
Fatty acid flux and oxidation are increased by rimonabant in obese women
}

\author{
Katharine Backhouse ${ }^{a, 1}$, Ivana Sarac ${ }^{a, 1}$, Fariba Shojaee-Moradie ${ }^{a}$, Michael Stolinski ${ }^{a}$, \\ M. Denise Robertson ${ }^{a}$, Gary S. Frost ${ }^{b}$, Jimmy D. Bell ${ }^{c}$, E. Louise Thomas ${ }^{c}$, John Wright ${ }^{a}$, \\ David Russell-Jones ${ }^{a}$, A. Margot Umpleby ${ }^{a, *}$ \\ ${ }^{a}$ Diabetes and Metabolic Medicine, Postgraduate Medical School, University of Surrey, Guildford, UK \\ ${ }^{\mathrm{b}}$ Nutrition and Dietetic Research Group, Department of Investigative Medicine, Hammersmith Hospital, Imperial College, London, UK \\ ${ }^{\mathrm{c}}$ Metabolic and Molecular Imaging Group, MRC Clinical Sciences Centre, Hammersmith Hospital, Imperial College, London, UK
}

A R T I C L E I N F O

Article history:

Received 19 January 2012

Accepted 23 February 2012

\begin{abstract}
A B S T R A C T
This study aimed to determine in obese women if endocannabinoid receptor antagonism has effects on fatty acid and triglyceride metabolism and insulin sensitivity which are independent from the metabolic effects of weight loss. Fourteen obese $\left(B M I=33.0 \pm 0.5 \mathrm{~kg} / \mathrm{m}^{2}\right)($ mean \pm SEM) Caucasian post-menopausal women, aged $57.8 \pm 4.7$ years were studied. The women were randomised to 2 groups, one group received the endocannabinoid receptor antagonist rimonabant $(20 \mathrm{mg} / \mathrm{d})$ for 12 weeks. A control group achieved the same weight loss by a hypocaloric dietary intervention over 12 weeks. Palmitate production rate (Ra), a measure of lipolysis, and palmitate oxidation rate, and $\mathrm{VLDL}_{1}$ and $\mathrm{VLDL}_{2}$ triglyceride (TG) kinetics, were measured using isotopic tracers before and after the intervention. Weight loss was not different in the 2 groups; $2.6 \pm 0.5 \mathrm{~kg}$ with rimonabant and $3.1 \pm 1.0 \mathrm{~kg}$ in the control group. Palmitate Ra increased with rimonabant with no change in the control group ( $\mathrm{p}=0.03$ between groups). Palmitate oxidation rate increased with rimonabant but decreased in the control group $(p=0.005$ between groups). VLDL $\mathrm{VL}_{1} \mathrm{TG}$ secretion rate decreased in the control group and increased in the rimonabant group ( $p=0.008$ between groups). There was no significant effect on insulin sensitivity. This study suggests that endocannabinoid receptor antagonism for 12 weeks in obese women increased lipolysis and fatty acid oxidation. The increase in $\mathrm{VLDL}_{1} \mathrm{TG}$ secretion rate may be due to the increase in lipolysis which exceeded the increase in fatty acid oxidation.

(c) 2012 Elsevier Inc. All rights reserved.
\end{abstract}

\section{Introduction}

The endocannabinoid system is involved in the physiological control of food intake and energy balance [1]. It is overactive in human obesity [2] and in diet-induced obese mice [3,4]. Mice with a genetic deletion in the CB1 cannabinoid receptor are leaner than their pair fed wild type littermates and when fed a high fat diet do not become obese or develop insulin

\footnotetext{
Abbreviation: FCR, fractional clearance rate; IHCL, intrahepatocellular lipid; IMCL, intramyocellular lipid; MCR, metabolic clearance rate; Ox, oxidation rate; Ra, production rate; REE, resting energy expenditure; SR, secretion rate; TEE, total energy expenditure; TG, triglyceride; VLDL, very low-density lipoprotein.

Clinical Trial Registration Number: NCT00584389.

* Corresponding author. Tel.: +01483 688579; fax: +01483 688501.

E-mail address: m.umpleby@surrey.ac.uk (A.M. Umpleby).

1 These authors made an equal contribution to this manuscript.
} 
resistance [5] suggesting they have increased energy expenditure. The CB1 antagonist rimonabant (SR141716) reduced food intake transiently in diet-induced obese mice, but a decrease in body weight was prolonged, also suggesting an effect on energy expenditure [6]. In ob/ob mice treated for 7 days with rimonabant, basal oxygen consumption increased $37 \%$ compared to control mice [7].

Three studies in obese subjects (BMI $33-38 \mathrm{~kg} / \mathrm{m}^{2}$ ) completing 12 months of treatment with rimonabant $(20 \mathrm{mg} / \mathrm{d})$ showed a mean weight loss from baseline of $8.5 \mathrm{~kg}$, accompanied by a decrease in plasma TG and an increase in insulin sensitivity [8-10]. Calculation of the expected metabolic effects of the body weight loss suggested that $50 \%$ of the improvements in TG and insulin sensitivity could not be attributed to weight loss per se [10].

Since weight loss can cause significant changes in metabolism, to determine the direct effects of rimonabant rather than those due to weight loss, this study compared changes in fatty acid and triglyceride metabolism in a rimonabanttreated group and a control group treated only with diet with weight loss matched for that achieved in the rimonabant group. To investigate whether rimonabant could induce weight loss due to effects on energy expenditure, energy intake was maintained at pre-treatment levels in the treatment group.

\section{Methods}

\subsection{Study design}

This study was registered with ClinicalTrials.gov (NCT00584389) and approved by the UK Medicines and Healthcare Products Regulatory Agency (Eudract 2006006424-18), the East Kent Ethics Committee and University of Surrey Ethics Committee. All subjects provided written informed consent. The study was powered for 30 obese (BMI 30-35 kg/m²) Caucasian post-menopausal women, randomised into two groups. The treatment group $(n=15)$ was to receive rimonabant $(20 \mathrm{mg} / \mathrm{d})$ for 12 weeks with energy intake matched to their energy requirements, determined during a 4 week run-in pre-treatment period. The control group $(n=15)$ was to follow a dietary intervention to achieve the same weight loss as the rimonabant group. Exclusion criteria are shown in the Supplement. The European Medicines Agency withdrew marketing authorisation for rimonabant in 2008, rimonabant was withdrawn from the market by Sanofiaventis, and the study was terminated. Studies had been completed in 14 women randomised into the rimonabant (age $58.1 \pm 1.9$ years; BMI $32.9 \pm 0.7$ ) and control group (age $57.4 \pm 1.9$ years; BMI $33.0 \pm 0.8$ ) ( $n=7 /$ group).

After recruitment and randomisation, participants entered a 4 week run-in period (see Supplement). At the end of this period the following measurements were made; whole body fat by bioimpedance, resting energy expenditure (REE) by indirect calorimetry, insulin sensitivity with a euglycemic hyperinsulinemic clamp, palmitate $\mathrm{Ra}, \mathrm{Ox}$ and metabolic clearance rate (MCR) with an infusion of ${ }^{13} \mathrm{C}$ palmitate and ${ }^{13} \mathrm{C}$ acetate, $\mathrm{VLDL}_{1}$ and $\mathrm{VLDL}_{2}$-TG secretion and $\mathrm{FCR}$, with an intravenous bolus of ${ }^{2} \mathrm{H}_{5}$ glycerol and IHCL and IMCL by magnetic resonance spectroscopy (see Supplement). These measurements were repeated after 12 weeks.

For laboratory methods and data analysis see the Supplement.

\subsection{Statistical analysis}

The results are presented as means \pm SEM. Within group changes were analysed by paired t test and changes between groups by t test using SPSS (version 16). Non parametric data were logarithmically transformed before analysis.

\section{Results}

During the run-in period TEE was not significantly different from energy intake confirming participants were not underreporting energy intake. Reported energy intake was maintained with rimonabant for 13 weeks and decreased in controls (Table 1) (Fig. 2, Supplement) due to a decrease in fat and carbohydrate intake (Table 2, Supplement). Weight loss, which was $2.6 \pm 0.5 \mathrm{~kg}$ with rimonabant $(p<0.003)$, and $3.1 \pm 1.0 \mathrm{~kg}$ in controls $(p<0.03)$ was not different between groups. There was a similar reduction in waist circumference and fat mass but no change in IHCL and IMCL in both groups (Table 1, Supplement). REE tended to decrease in controls $(p=0.055)$, as expected with weight loss but was maintained with rimonabant despite

Table 1 - Energy balance, hormones, lipids and insulin sensitivity.

\begin{tabular}{|c|c|c|c|c|c|}
\hline & \multicolumn{2}{|c|}{ Rimonabant Group } & \multicolumn{2}{|c|}{ Control Group } & \multirow{2}{*}{$\begin{array}{l}\Delta \text { rimonabant } \\
\text { vs } \Delta \text { control }\end{array}$} \\
\hline & Week 0 & Week 12 & Week 0 & Week 12 & \\
\hline Energy intake (kcal/day) & $1991 \pm 99$ & $1963 \pm 73$ & $1906 \pm 36$ & $1564 \pm 56^{*}$ & $p=0.002$ \\
\hline REE (kcal/day) & $1434 \pm 59$ & $1436 \pm 50$ & $1453 \pm 76$ & $1386 \pm 76^{\ddagger}$ & NS \\
\hline Glucose (mmol/l) & $5.6 \pm 0.2$ & $5.4 \pm 0.1$ & $5.4 \pm 0.2$ & $5.4 \pm 0.2$ & NS \\
\hline GIR/I $(\mu \mathrm{g} / \mathrm{kg} / \mathrm{min} /[\mathrm{pmol} / \mathrm{l}])$ & $5.07 \pm 1.09$ & $6.04 \pm 1.41$ & $5.80 \pm 1.12$ & $6.06 \pm 1.07$ & NS \\
\hline Triglyceride (mmol/l) & $1.6 \pm 0.6$ & $1.7 \pm 0.5$ & $1.2 \pm 0.1$ & $0.9 \pm 0.1^{\dagger}$ & NS \\
\hline Cholesterol (mmol/l) & $5.6 \pm 0.5$ & $5.4 \pm 0.7$ & $5.3 \pm 0.4$ & $5.0 \pm 0.5$ & NS \\
\hline HDL-Cholesterol (mmol/l) & $1.39 \pm 0.13$ & $1.49 \pm 0.13^{\ddagger}$ & $1.32 \pm 0.05$ & $1.55 \pm 0.07^{*}$ & NS \\
\hline Adiponectin $(\mu \mathrm{g} / \mathrm{ml})$ & $12.0 \pm 1.4$ & $11.9 \pm 1.5$ & $11.3 \pm 1.7$ & $10.8 \pm 1.8^{\dagger}$ & NS \\
\hline Leptin $\mathrm{ng} / \mathrm{ml}$ & $23.5 \pm 2.9$ & $20.6 \pm 3.0^{*}$ & $19.5 \pm 1.5$ & $16.8 \pm 1.7^{*}$ & NS \\
\hline
\end{tabular}


Table 2 - Palmitate and VLDL kinetics.

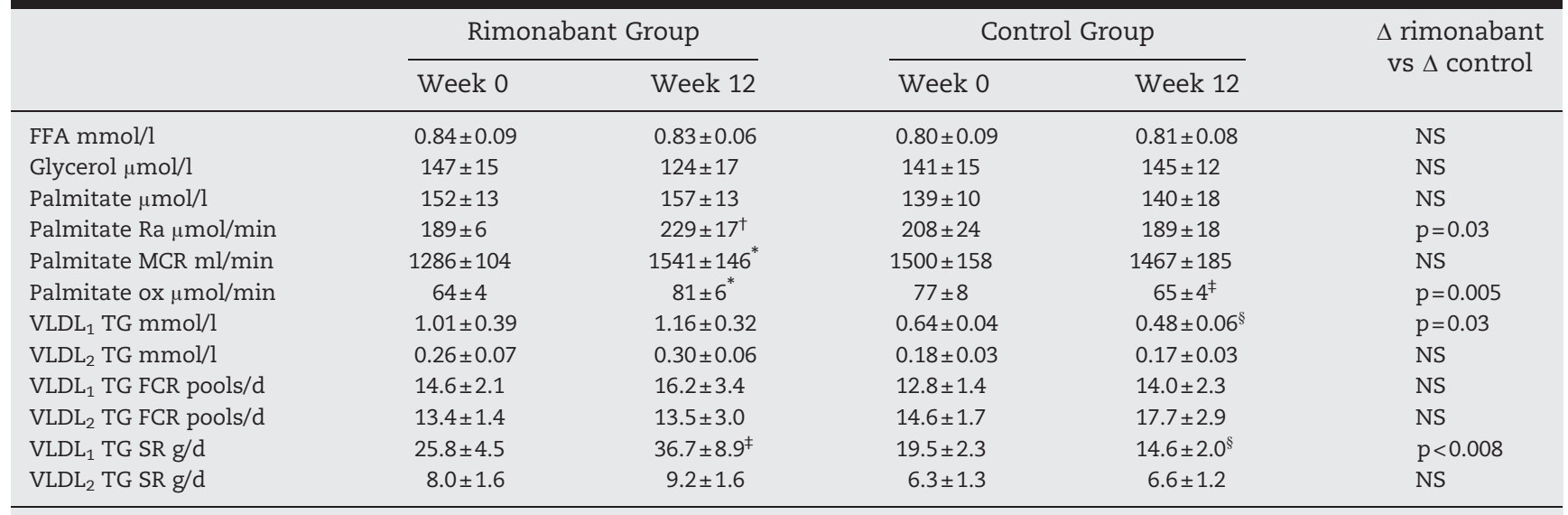

SR, secretion rate; FCR, fractional catabolic rate; MCR, metabolic clearance rate; ox, oxidation rate Ra, rate of appearance. $n=6$ for palmitate kinetics in the rimonabant group due to compromised venous access during the palmitate tracer infusion in 1 subject; significantly different from 0 weeks, ${ }^{\dagger} p<0.05,{ }^{*} p=0.05, \neq p=0.06, \S p=0.07$

weight loss. Insulin sensitivity, increased in both groups but was not statistically significant (Table 1).

The change in palmitate Ra over 12 weeks was significantly different between groups $(p=0.03)$ with a within group increase $(p<0.05)$ with rimonabant (Table 2$)$. Palmitate MCR also increased $(p=0.05)$ with rimonabant. There was no change in these measurements in the control group. Palmitate Ox increased with rimonabant and decreased in controls with a difference between groups $(p=0.005)$. Palmitate Ra, and Ox were also different between groups when expressed per $\mathrm{kg}$ of fat free mass $(p=0.03$, $\mathrm{p}=0.01$ ). When expressed per $\mathrm{kg}$ of fat mass palmitate $\mathrm{Ra}$ increased with rimonabant $(p=0.02)$ and was different between groups $(p=0.04)$.

Plasma TG decreased in controls $(p<0.05)$ but did not change with rimonabant (Table 1$)$. $\mathrm{VLDL}_{1}$ TG concentration decreased in controls $(p=0.07)$. $\mathrm{VLDL}_{1} \mathrm{SR}$ increased with rimonabant and decreased in controls $(p<0.008$ between groups) (Table 2).

\section{Discussion}

This study demonstrated that the CB1 receptor antagonist rimonabant had metabolic effects which were independent of weight loss. Using stable isotope techniques it was shown that palmitate Ra, a measure of lipolysis, and palmitate MCR increased after rimonabant treatment for 12 weeks. Palmitate Ox also increased with rimonabant, in contrast to the controls where palmitate Ox decreased. VLDL TG kinetics were also different in the 2 groups with an increase in $\mathrm{VLDL}_{1}$ TG SR with rimonabant but a decrease in the control group suggesting that the increased lipolysis with rimonabant treatment may have driven an increase in hepatic TG synthesis. REE decreased in the controls but did not decrease with rimonabant despite similar weight loss suggesting an effect on energy expenditure.

This is the first demonstration that palmitate oxidation is increased with a CB1 receptor antagonist in humans and importantly confirms previous animal studies. In rats fed a high fat diet, rimonabant treatment increased the oxygen consumption of liver mitochondria and increased fatty acid entry into liver mitochondria via CPT I [11]. Increased hepatic CPT1 activity has also been reported in mice fed a high fat diet and treated with rimonabant [12]. The peripheral CB1 receptor antagonist, AM6545 has also been shown to increase fat oxidation, in mice fed either a standard laboratory diet or a high fat diet [13].

This is also the first demonstration in humans that a CB1 receptor antagonist increases lipolysis. Adipocytes express CB1 receptors and endocannabinoids have been shown to inhibit lipolysis via inhibition of adenylate cyclase [14]. CB1 receptors are also present on peripheral sympathetic nerve terminals where they mediate inhibition of norepinephrine release [15]. Blockade of these receptors by rimonabant is another possible mechanism for the increase in lipolysis in adipose tissue which is highly innervated by the SNS.

The decrease in plasma TG in the controls was in $\mathrm{VLDL}_{1}$ due to a decrease in $\mathrm{VLDL}_{1}$ TG secretion. Previous studies have also shown weight loss due to caloric restriction to decrease VLDL TG secretion [16]. Despite similar weight loss with rimonabant $\mathrm{VLDL}_{1}$ TG secretion increased. Since the increase in palmitate $\mathrm{Ra}$ was greater than the increase in palmitate oxidation rate with rimonabant, $\mathrm{VLDL}_{1}$ secretion may have increased due to an increased delivery of fatty acids to the liver driving $\mathrm{VLDL}_{1}$ synthesis. This contrasts with the large rimonabant clinical trials in which plasma TG decreased after 52 weeks when weight was beginning to stabilize. After 12 weeks [8-10], the rate of weight loss would be expected to be high. Treatment of both diet induced mice and $o b / o b$ mice with the peripheral CB1 receptor antagonist, AM6545 for 7 days was also shown to increase TG secretion [13].

One aim of the study had been to investigate whether weight loss would occur due to increased energy expenditure if calorie intake could be maintained in the rimonabant group. The lack of a decrease in REE with rimonabant, despite weight loss, suggests there was an effect on energy expenditure. Strack et al (2011) also found total EE measured 
with double labelled water did not decrease following pharmacologic inhibition of the CB1 receptor in a canine model despite an $11 \%$ reduction in body weight, whereas total EE decreased in a food restricted control group with only $6 \%$ weight loss [17].

This is a small study, reduced in size due to the withdrawal of rimonabant during the trial and therefore may be limited by lack of power to detect some differences. Nevertheless the demonstration of metabolic changes in a small study shows the powerful effect of rimonabant on lipolysis and fatty acid oxidation in obese humans which could be detected using isotopic tracers. Further studies of the role of the endocannabinoid system in the control of fatty acid metabolism and energy balance may lead to the development of anti-obesity drugs which do not have the unacceptable side effects of rimonabant.

Supplementary materials related to this article can be found online at doi:10.1016/j.metabol.2012.02.012.

\section{Author contributions}

AMU, GF, DRJ and MDR designed the study. IS, KB, FSM, MS, JW and MDR performed the clinical studies. DRJ supervised the trial. IS, MS and FSM performed the laboratory work, supervised by AMU. KB supervised the diets and measured energy balance guided by GF. JB and ELT measured IHCL and IMCL. All authors made a contribution to the paper. AMU was the lead writer.

\section{Funding}

This trial was funded by the EFSD, the University of Surrey PhD scholarship fund (for IS) and the British Medical Research Council (MRC).

\section{Acknowledgment}

We thank Sanofi-aventis for supplying the rimonabant, Sunil Zachariah and Ben Sheldon for medical assistance, Michelle Gibbs for dietary advice, Roman Hovorka for modeling assistance, Nicola Jackson and Jo Batt for technical assistance.

\section{Conflict of Interest}

IS, KB, FSM, MS, JW, GF, MDR and AMU have no conflict of interest. DRJ is a member of advisory boards for GSK, Novartis, Novo Nordisk and has been on advisory boards for Eli Lilly, Pharmacia Upjohn, Aventis. He receives honoraria for invited talks from some of these companies and has received research grants from Takeda, Eli Lilly, Novo Nordisk, Boehringer Engleheim and Pharmacia Upjohn.

\section{R E F E R E N C E S}

[1] Di Marzo V, Matias I. Endocannabinoid control of food intake and energy balance. Nat Neurosci 2005;8:585-9.

[2] Engeli S, Bohnke J, Feldpausch M, et al. Activation of the peripheral endocannabinoid system in human obesity. Diabetes 2005;54:2838-43.

[3] Osei-Hyiaman D, DePetrillo M, Pacher P, et al. Endocanna binoid activation at hepatic CB1 receptors stimulates fatty acid synthesis and contributes to diet-induced obesity. J Clin Invest 2005;115:1298-305.

[4] Matias I, Gonthier MP, Orlando P, et al. Regulation, function, and dysregulation of endocannabinoids in models of adipose and beta-pancreatic cells and in obesity and hyperglycemia. J Clin Endocrinol Metab 2006;91:3171-80.

[5] Ravinet Trillou C, Delgorge C, Menet C, et al. CB1 cannabinoid receptor knockout in mice leads to leanness, resistance to diet-induced obesity and enhanced leptin sensitivity. Int J Obes Relat Metab Disord 2004;284:640-8.

[6] Jbilo O, Ravinet-Trillou C, Arnone M, et al. The CB1 receptor antagonist rimonabant reverses the diet-induced obesity phenotype through the regulation of lipolysis and energy balance. Faseb J 2005;19:1567-9.

[7] Liu YL, Connoley IP, Wilson CA, et al. Effects of the cannabinoid CB1 receptor antagonist SR141716 on oxygen consumption and soleus muscle glucose uptake in Lep(ob)/Lep(ob) mice. Int J Obes 2005;29:183-7.

[8] Despres JP, Golay A, Sjostrom L. Effects of rimonabant on metabolic risk factors in overweight patients with dyslipidemia. N Engl J Med 2005;353:2121-34.

[9] Van Gaal LF, Rissanen AM, Scheen AJ, et al. Effects of the cannabinoid-1 receptor blocker rimonabant on weight reduction and cardiovascular risk factors in overweight patients: 1-year experience from the RIO-Europe study. Lancet 2005;365:1389-97.

[10] Pi-Sunyer FX, Aronne LJ, Heshmati HM, et al. RIO-North America Study Group. Effect of rimonabant, a cannabinoid-1 receptor blocker, on weight and cardiometabolic risk factors in overweight or obese patients: RIO-North America: a randomized controlled trial. JAMA 2006;295:761-75.

[11] Flamment M, Gueguen N, Wetterwald C, et al. Effects of the cannabinoid CB1 antagonist, rimonabant, on hepatic mitochondrial function in rats fed a high fat diet. Am J Physiol Endocrinol Metab 2009;297:E1162-170.

[12] Osei-Hyiaman D, Liu J, Zhou L, et al. Hepatic CB1 receptor is required for development of diet-induced steatosis, dyslipidemia, and insulin and leptin resistance in mice. J Clin Invest 2008;118:3160-9.

[13] Tam J, Vemuri VK, Liu J, et al. Peripheral CB1 cannabinoid receptor blockade improves cardiometabolic risk in mouse models of obesity. J Clin Invest 2010;120:2953-66.

[14] di marzo V. The endocannabinoid system in obesity and type 2 diabetes. Diabetologia 2008;51:1356-67.

[15] Ishac EJ, Jiang L, Lake KD, et al. Inhibition of exocytotic noradrenaline release by presynaptic cannabinoid CB1 receptors on peripheral sympathetic nerves. $\mathrm{Br} \mathrm{J}$ Pharmacol 1996;118:2023-8.

[16] Mittendorfer B, Patterson BW, Klein S. Effect of weight loss on VLDL-triglyceride and apoB-100 kinetics in women with abdominal obesity. Am J Physiol Endocrinol Metab 2003;284: E549-56.

[17] Strack AM, Nicolich S, Faidley T, et al. Cannabinoid-1 receptor inhibition prevents the reduction of 24-hour energy expenditure with weight loss. Metabolism 2011, doi:10.1016/j.metabol.2011.09.002. 